\title{
Effect of xylazine, medetomidine and dexmedetomidine on cardiac conduction in pigs ${ }^{1) 2}$
}

\author{
ALICJA CEPIEL, AGNIESZKA NOSZCZYK-NOWAK, ADRIAN JANISZEWSKI*, \\ ROBERT PASŁAWSKI**, URSZULA PASŁAWSKA

\begin{abstract}
Department of Internal Diseases with Clinic of Diseases of Horses, Dogs and Cats,
*Centre for Experimental Diagnostics and Biomedical Innovations, Faculty of Veterinary Medicine,

Wroclaw University of Environmental and Life Sciences, pl. Grunwaldzki 47, 50-366, Wrocław, Poland

**Department and Clinic of Internal and Occupational Diseases and Hypertension, Wroclaw Medical University,
\end{abstract} \\ ul. Borowska 213, 50-556 Wrocław, Poland
}

Cepiel A., Noszczyk-Nowak A., Janiszewski A., Pasławski R., Pasławska U.

Effect of xylazine, medetomidine and dexmedetomidine on cardiac conduction in pigs

\section{Summary}

The majority of anaesthetics used in studies regarding heart arrhythmias may affect the cardiac conduction system, thus influencing the results. In veterinary medicine, xylazine, medetomidine and dexmedetomidine are commonly used for premedication in laboratory and companion animals. To date, there have been no studies assessing the effect of these substances on the cardiac conduction system. The aim of this study was to assess the effect of xylazine, medetomidine and dexmedetomidine on the parameters of the cardiac conduction system in pigs. The study was carried out on 18 Great White Polish male pigs weighing from 21 to $40 \mathrm{~kg}$. The animals were divided into three equal groups. The animals from the first group received xylazine at a dose of $2 \mathrm{mg} /$ $\mathrm{kg}$ i.v.; those from the second group received medetomidine at $40 \mathrm{mcg} / \mathrm{kg}$ i.v.; and those from the third group received dexmedetomidine at $10 \mathrm{mcg} / \mathrm{kg}$ i.v. The electrophysiological activity of the heart was analysed using an invasive electrophysiological study (EPS). During the EPS, a decrease in the heart rate after substance administration was observed in all animals, but there were no statistically significant differences in the cardiac conduction parameters. A pro-arrhythmic effect of xylazine was observed, but no statistically significant changes in the EPS parameters were noted. Our results indicate that medetomidine and dexmedetomidine may be used as standard premedication drugs in electrophysiological studies in pigs. Their use may facilitate animal preparation procedures without affecting study results.

Keywords: xylazine, medetomidine, dexmedetomidine, EPS, pigs

Pigs are widely used as models to study the cardiovascular, gastrointestinal, reproductive, excretory and integumentary systems $(1,2,6,9,20,21,28)$. Pigs are also used as models in immunology, transplantology, gene therapy, toxicology, neurology, oncology and regenerative medicine $(4,7,11,13,35)$. Pig models are considered valuable because of their physiological and anatomical similarities to humans. They became increasingly popular in cardiac surgery and were used as heart transplantation models in Poland in the late 1990s. The majority of studies require the animal to be immobilised or fully anesthetised. Most of anaesthetics

Award for the best presentation of young scientists on the Section of Farm Animal Diseases during XV Congress of Polish Society of Veterinary Sciences in Lublin 22-24.09.2016.

The study was conducted by financing by targeted subsidy and statute subsidy of the Department of Internal Diseases with the Clinic of Horses, Dogs and Cats. affect and change the physiology of the body systems, particularly the circulatory system $(21,22,29,30)$. This effect is particularly significant in cardiac arrhythmia studies. Hence, new anaesthetics are constantly sought, and the effects of the available anaesthetic drugs are being widely studied. The most common drugs used to anesthetise pigs include midazolam, azaperon, fentanyl, droperidol, ketamine and barbiturates $(5,19,36)$. Alpha-2 adrenergic agonists, which are commonly used in companion animals, are rarely used in laboratory animals prior to cardiovascular procedures, because they reduce the blood pressure and heart rate. To date, there have been no studies assessing the precise impact of the anaesthetics used in pigs on the specific parts of the cardiac conduction system.

Xylazine, medetomidine and dexmedetomidine, alpha-2 adrenergic receptor agonists that have an 
imidazole ring in their structure, are widely used for premedication, alone or in combination with other drugs. They have sympatholytic, sedative, hypnotic, analgesic and slight muscle relaxing properties. Studies have shown that there are at least five different effector mechanisms triggered by the activation of alpha-2 adrenergic receptors, including inhibition of adenylate cyclase, the acceleration of the sodium and hydrogen ion exchange across cell membranes, the activation of potassium ion channels, the inhibition of voltageoperated calcium ion channels and modulation of the activity of phospholipase $\mathrm{C}$ in cell membranes. Alpha-2 mimetics can also be classified from a practical point of view, on the basis of their effect on alpha-1 and alpha-2 receptors. The alpha-2:alpha-1 receptor selectivity amounts to $160: 1$ for xylazine and $1620: 1$ for medetomidine and dexmedetomidine (26). Xylazine is the least selective of the three drugs, but is popularly used in veterinary medicine. Dexmedetomidine is the newest of these drugs and is an active enantiomer isolated from a racemised mixture of medetomidine. It is more active and gives longer-lasting analgesia at the same dose as medetomidine.

The aim of the study was to assess the effect of xylazine, medetomidine and dexmedetomidine on the successive parts of the cardiac conduction system in pigs.

\section{Material and methods}

The study was carried out on 18 Great White Polish male pigs weighing from 21 to $40 \mathrm{~kg}$. The animals were divided into three groups, each containing six pigs. The animals from the first group received xylazine at a dose of $2 \mathrm{mg} / \mathrm{kg}$ i.v.; pigs from the second group received medetomidine at $40 \mathrm{mcg} / \mathrm{kg}$ i.v.; and those from the third group received dexmedetomidine at $10 \mathrm{mcg} / \mathrm{kg}$ i.v. $(8,25,32)$. The clinical status of the animals was assessed on the basis of a complete blood cell count and biochemical analysis (ALT, AST, urea, creatinine, $\mathrm{Na}^{+}, \mathrm{K}^{+}, \mathrm{Mg}^{2+}, \mathrm{Cl}^{-}$, glucose, CRP) and an electrocardiography examination, in which the heart rate, sinus rhythm, presence of arrhythmias and basic ECG parameters (P wave, T wave, QRT complex, PQ, QT and QTc interval) were assessed. The electrophysiological properties of the heart were measured via an invasive electrophysiological study carried out with a BARD Electrophysiology LABSYSTEM PRO system. Four-pole electrodes with different curvature values, including a BARD Electrophysiology Cournand Curve and Josephson Curve, were used. All the electrodes were size $6 \mathrm{~F}$. The procedure was carried out under inhaled general anaesthesia using $1.5-2 \%$ Vol isoflurane, after premedication with midazolam at $30 \mathrm{mg} / \mathrm{m}^{2}$ and induction of sleep with propofol $(2 \mathrm{mcg} /$ $\mathrm{kg} / \mathrm{min}$ ). The anesthetized animals were placed in dorsal recumbency, and the Seldinger method was used to place a catheter in the right and left external jugular veins and the left femoral vein (3). Two or three electrodes were inserted into the right atrium, coronary sinus, bundle of His and right ventricle through vascular sheaths under fluoroscopy and intracardiac potential guidance. The first (passive) part of the study consisted of the registration of intracardiac poten- tials from the right atrium, coronary sinus, bundle of His and right ventricle during the sinus rhythm. In the second, dynamic part of the study, selected regions of the heart were stimulated. The electrophysiological study was carried out at two time points: prior to and 15 minutes after intravenous administration of the anaesthetics. Basic conduction parameters during a normal rhythm and during the programmed stimulation according to the previously described protocol were recorded in the EPS. All the parameters were recorded in milliseconds (ms). At the end of the study, the animals were euthanised.

The following parameters were recorded in the first part of the study: the HRA-LA (interatrial conduction time) from the high right atrium electrodes and coronary sinus; the $\mathrm{AH}$ interval (interval between the right atrium and the bundle of His) and the HV (interval between the area of the bundle of His and the ventricle) recorded from the electrodes in the right ventricle and the area of the bundle of His. The HRA-LA, which was the interatrial conduction time, was measured from the start of the impulse at the top of the atrium to the left atrium registered at the distal part of the coronary sinus. The AH was measured from the atrial deflection to the His bundle deflection. The HV was measured from the His bundle deflection to the earliest ventricular activation visible in the intracardiac electrocardiogram.

The following stimulation protocols were carried out during the dynamic phase:

- gradual atrial stimulation with a shortening cycle length to determine the Wenckebach point. The Wenckebach point is the lowest atrial stimulation frequency at which there is an AV delay, causing a Wenckebach block,

- continuous 30-second atrial stimulation using a $400 \mathrm{~ms}$ cycle in order to determine the sinus node recovery time (SNRT). The time from the last induced atrial stimulation to the resuming of the sinus rhythm atrial stimulation was recorded. In addition, the corrected sinus node recovery time (CSNRT), which was the sinus node recovery time minus the sinus cycle length, was recorded,

- a programmed atrial and ventricular stimulation with an additional impulse of a gradually shortening feedback in order to determine the atrial effective refractory period (AERP), the atrioventricular nodal effective refractory period (AVNERP) and the ventricular effective refractory period (VERP). The atrial effective refractory period is the longest interval between the last paced beat (S1-S1) and premature beats (S2), which does not cause premature atrial depolarization. The atrioventricular nodal effective refractory period is the longest interval between S1-S2, during which the stimulation is not conducted from the atrium to the ventricles. VERP is the longest S1-S2 interval, after which there is contraction of the ventricles. The refractory period was measured during the normal rhythm as well as induced heart rates of 130 beats/min ( $460 \mathrm{~ms}$ cycle), 150 beats $/ \mathrm{min}$ ( $400 \mathrm{~ms}$ cycle) and 180 beats $/ \mathrm{min}$ ( $330 \mathrm{~ms}$ cycle $)$, in an $8+1$ system ( 8 stimulated impulses and 1 impulse with a shortened cycle),

- a short-term continuous stimulation, lasting $400 \mathrm{~ms}$ and originating in the atrium, was recorded in order to determine interatrial conduction during an imposed rhythm (HRA-LA $150 / \mathrm{min}$ ); another stimulation originating in the 
coronary sinus was recorded in order to assess interatrial conduction during an imposed rhythm (LA-HRA 150/min).

Statistical analyses were carried out using version $12.0 \mathrm{PL}$ of Statistica. The differences between the groups for related and unrelated parametric data with a normal distribution were assessed using Student's t-test. Non-parametric data or data with a non-normal distribution were assessed using Friedman's ANOVA and the Kendall coefficient for multiple related variable groups or Kruskal-Wallis ANOVA for multiple variable unrelated groups. The correlations were analysed using Spearman $\mathrm{R}$ test. Statistical significance was set at $\mathrm{p} \leq 0.05$.

The study was approved by the Second Local Ethics Committee for Experiments on Animals, permit no 8/2015 from 18.02.2015.

\section{Results and discussion}

The results of the complete blood count and blood biochemical analysis were within reference ranges (18). In all the animals, the resting EKG did not reveal any abnormalities. All the animals had a lower heart rate in the course of the EPS following the administration of alpha-2-adrenergic receptors. After administering xylazine, the mean heart rate decreased from 97 $(\mathrm{SD} \pm 12)$ bmp to $78(\mathrm{SD} \pm 5) \mathrm{bmp}$. It decreased from $117(\mathrm{SD} \pm 13)$ bmp to $86(\mathrm{SD} \pm 8)$ bmp following the administration of medetomidine and from 133 (SD $\pm 18) \mathrm{bmp}$ to $94(\mathrm{SD} \pm 4$ ) bmp after administering dexmedetomidine. There were no statistically significant differences in the cardiac conduction parameters in group I. In groups II and III, there were statistically significant differences in the effective refractory period (ERPV 130) of the right ventricle at an induced rhythm of $130 / \mathrm{min}$. The values of the parameters in the groups are presented in Tables 1-3. In the group of animals receiving medetomidine, the mean refractory period of the ventricles at an induced rhythm of 130/ min increased from $198 \mathrm{~ms}(\mathrm{SD} \pm 21)$ to $228 \mathrm{~ms}$ (SD \pm 18 ). In the group receiving dexmedetomidine, this period increased from $203 \mathrm{~ms}(\mathrm{SD} \pm 18)$ to $218 \mathrm{~ms}$ $(\mathrm{SD} \pm 19)$. In addition, an arrhythmogenic effect of the substances was observed. In group I, four pigs developed arrhythmias following xylazine administration, atrial flutter was observed in three of them (Fig. 1) and supraventricular tachycardia in one pig. In one pig from group I, the atrial flutter prevented the identification of the atrial effective refractory period and the atrioventricular effective refractory period under induced rhythms of $130 / \mathrm{min}$ and $150 / \mathrm{min}$. Atrial flutter was also observed in two pigs in group II receiving medetomidine and in one pig in group III receiving dexmedetomidine.

No statistically significant differences in the cardiac conduction parameters following the administration of the three substances were found despite their substantial effects on the heart rate. The results may be affected by the other substances used in the anaesthesia of pigs, including isoflurane, midazolam and propofol. Previous studies have shown that inhalation

Tab. 1. Values of the electrophysiological parameters in the pigs before and after administration of xylazine (milliseconds)

\begin{tabular}{|c|c|c|c|c|c|c|c|c|c|c|c|c|c|c|}
\hline \multirow{2}{*}{ Parameter } & \multicolumn{2}{|c|}{ Pig 1} & \multicolumn{2}{|c|}{ Pig 2} & \multicolumn{2}{|c|}{ Pig 3} & \multicolumn{2}{|c|}{ Pig 4} & \multicolumn{2}{|c|}{ Pig 5} & \multicolumn{2}{|c|}{ Pig 6} & \multicolumn{2}{|c|}{ Mean value $( \pm \mathrm{SD})$} \\
\hline & Before & After & Before & After & Before & After & Before & After & Before & After & Before & After & Before & After \\
\hline HV & 31 & 34 & 40 & 24 & 35 & 34 & 41 & 60 & 34 & 30 & 43 & 82 & $37 \pm 4.7$ & $44 \pm 22.3$ \\
\hline HRA-LA & 42 & 38 & 48 & 50 & 70 & 72 & 60 & 66 & 82 & 66 & 38 & 82 & $57 \pm 17.1$ & $62 \pm 15.8$ \\
\hline HRA-LA 150 & 56 & 76 & 72 & 94 & 70 & 96 & 82 & 72 & 100 & 106 & 88 & 76 & $78 \pm 15.1$ & $87 \pm 13.8$ \\
\hline LA-HRA 150 & 156 & 212 & 72 & 78 & 72 & 96 & 80 & 72 & 100 & 110 & 88 & 49 & $95 \pm 31.9$ & $103 \pm 57.4$ \\
\hline AV Wenckebach & 200 & 190 & 200 & 210 & 200 & 230 & 200 & 240 & 200 & 220 & 200 & 200 & $200 \pm 0$ & $215 \pm 18.7$ \\
\hline SNRT & 716 & 1018 & 750 & 882 & 914 & 786 & 648 & 788 & 948 & 1068 & 638 & 816 & $769 \pm 132.7$ & $893 \pm 122.3$ \\
\hline CSNRT & 94 & 154 & 72 & 108 & 122 & 114 & 80 & 66 & 112 & 184 & 68 & 94 & $91 \pm 22.0$ & $120 \pm 42.5$ \\
\hline VERP 130 & 230 & 180 & 240 & 240 & 240 & 260 & 220 & 230 & 220 & 230 & 270 & 300 & $237 \pm 18.6$ & $240 \pm 39.5$ \\
\hline VERP 150 & 230 & 170 & 220 & 230 & 190 & 240 & 220 & 220 & 200 & 240 & 270 & 310 & $222 \pm 27.9$ & $235 \pm 45.1$ \\
\hline VERP 180 & 160 & 160 & 190 & 190 & 190 & 210 & 190 & 210 & 180 & 240 & 230 & 340 & $190 \pm 22.8$ & $225 \pm 62.2$ \\
\hline AERP 130 & 110 & 140 & 120 & 150 & 140 & * & 140 & 160 & 150 & 130 & 130 & 150 & $132 \pm 14.7$ & $146 \pm 11.4$ \\
\hline AERP 150 & 110 & 130 & 110 & 140 & 130 & * & 130 & 160 & 140 & 120 & 140 & 140 & $127 \pm 13.7$ & $138 \pm 14.8$ \\
\hline AVNERP 130 & 250 & 250 & 280 & 150 & 310 & * & 250 & 290 & 290 & 310 & 290 & 300 & $278 \pm 24.0$ & $260 \pm 65.6$ \\
\hline AVNERP 150 & 250 & 230 & 270 & 280 & 280 & * & 270 & 270 & 300 & 280 & 290 & 270 & $277 \pm 17.5$ & $266 \pm 20.7$ \\
\hline HR & 98 & 78 & 94 & 71 & 83 & 80 & 88 & 85 & 104 & 80 & 118 & 74 & $97 \pm 12.4$ & $78 \pm 4.9$ \\
\hline
\end{tabular}

Explanations: HV - interval between His bundle electrogram and ventricular electrogram; SNRT - sinus node recovery time; CSNRT corrected sinus node recovery time; HRA-LA - conduction time between high right atrium and left atrium; HRA-LA 150 - conduction time between high right atrium and left atrium on a pacemaker set at 150/min; LA-HRA 150 - retrograde conduction time from left atrium to high right atrium at an externally induced heart rate of 150/min; AV Wenckebach - the lowest atrial stimulation frequency at which there is an AV delay, in a $1: 1$ ratio; AERP 130,150 - atrial effective refractory period during an externally induced heart rate of 130/min and 150/min; AVNERP 130, 150 - atrioventricular node effective refractory period during an externally induced heart rate of 130/min and 150/min; VERP 130/min, 150/min, 180/min - ventricular effective refractory period on a pacemaker set at 130/min, 150/min, 180/min; * not recorded; SD - standard deviation 
Tab. 2. Values of the electrophysiological parameters in the pigs before and after administration of medemtonidine (milliseconds)

\begin{tabular}{|c|c|c|c|c|c|c|c|c|c|c|c|c|c|c|}
\hline \multirow{2}{*}{ Parameter } & \multicolumn{2}{|c|}{ Pig 1} & \multicolumn{2}{|c|}{ Pig 2} & \multicolumn{2}{|c|}{ Pig 3} & \multicolumn{2}{|c|}{ Pig 4} & \multicolumn{2}{|c|}{ Pig 5} & \multicolumn{2}{|c|}{ Pig 6} & \multicolumn{2}{|c|}{ Mean value ( \pm SD) } \\
\hline & Before & After & Before & After & Before & After & Before & After & Before & After & Before & After & Before & After \\
\hline AH & 81 & 96 & 78 & 83 & 72 & 75 & 67 & 78 & 72 & 66 & 67 & 71 & $73 \pm 5.7$ & $78 \pm 18.3$ \\
\hline HV & 40 & 55 & 44 & 44 & 27 & 37 & 45 & 41 & 46 & 45 & 51 & 47 & $42 \pm 8.2$ & $45 \pm 6.1$ \\
\hline HRA-LA & 50 & 54 & 54 & 64 & 42 & 46 & 60 & 58 & 40 & 50 & 54 & 54 & $50 \pm 7.7$ & $54 \pm 6.2$ \\
\hline HRA-LA 150 & 86 & 104 & 78 & 100 & 80 & 76 & 90 & 72 & 76 & 74 & 60 & 72 & $78 \pm 10.1$ & $84 \pm 14.8$ \\
\hline LA-HRA 150 & 104 & 108 & 70 & 96 & 82 & 84 & 90 & 80 & 72 & 74 & 134 & 70 & $92 \pm 24.1$ & $85 \pm 14.3$ \\
\hline AV Wenckebach & 240 & 230 & 180 & 180 & 180 & 200 & 190 & 180 & 190 & 190 & 200 & 200 & $197 \pm 22.5$ & $197 \pm 18.6$ \\
\hline SNRT & 782 & 768 & 772 & 838 & 818 & 970 & 840 & 886 & 770 & 744 & 890 & 808 & $812 \pm 47.3$ & $836 \pm 82.9$ \\
\hline CSNRT & 94 & 76 & 104 & 130 & 198 & 200 & 182 & 144 & 54 & 58 & 212 & 76 & $141 \pm 65.0$ & $114 \pm 54.0$ \\
\hline VERP 130 & 230 & 260 & 180 & 210 & 210 & 230 & 200 & 240 & 190 & 220 & 180 & 210 & $198 \pm 19.4$ & $228 \pm 19.4$ \\
\hline VERP 150 & 210 & 240 & 170 & 200 & 200 & 160 & 190 & 210 & 180 & 200 & 180 & 200 & $188 \pm 14.7$ & $201 \pm 25.6$ \\
\hline VERP 180 & 180 & 220 & 170 & 180 & 180 & 160 & 190 & 210 & 180 & 190 & 170 & 190 & $178 \pm 7.5$ & $192 \pm 21.4$ \\
\hline AERP 130 & 140 & 130 & 110 & 130 & 110 & 100 & 130 & 130 & 130 & 130 & 130 & 130 & $125 \pm 12.2$ & $125 \pm 12.2$ \\
\hline AERP 150 & 130 & 130 & 110 & 120 & 110 & 100 & 120 & 130 & 130 & 120 & 130 & 130 & $122 \pm 9.8$ & $122 \pm 11.7$ \\
\hline AVNERP 130 & 320 & 280 & 230 & 230 & 240 & 230 & 270 & 270 & 280 & 290 & 200 & 250 & $257 \pm 42.3$ & $258 \pm 25.6$ \\
\hline AVNERP 150 & 290 & 290 & 210 & 210 & 230 & 230 & 240 & 250 & 270 & 270 & 270 & 260 & $252 \pm 29.9$ & $252 \pm 28.6$ \\
\hline HR & 104 & 74 & 120 & 90 & 130 & 80 & 126 & 88 & 98 & 90 & 128 & 97 & $118 \pm 13.5$ & $87 \pm 8.2$ \\
\hline
\end{tabular}

Explanations: AH - interval between atrial electrogram and His bundle electrogram; HV - interval between His bundle electrogram and ventricular electrogram; SNRT - sinus node recovery time; CSNRT - corrected sinus node recovery time; HRA-LA - conduction time between high right atrium and left atrium; HRA-LA 150 - conduction time between high right atrium and left atrium on a pacemaker set at 150/min; LA-HRA 150 - retrograde conduction time from left atrium to high right atrium at an externally induced heart rate of 150/min; AV Wenckebach - the lowest atrial stimulation frequency at which there is an AV delay, in a $1: 1$ ratio; AERP 130, 150 - atrial effective refractory period during an externally induced heart rate of 130/min and 150/min; AVNERP 130, 150 atrioventricular node effective refractory period during an externally induced heart rate of 130/min and 150/min; VERP 130/min, 150/min, 180/min - ventricular effective refractory period during an externally induced heart rate of 130/min, 150/min, 180/min; $\mathrm{SD}$ - standard deviation

Tab. 3. Values of the electrophysiological parameters in the pigs before and after administration of dexmedemtonidine (milliseconds)

\begin{tabular}{|c|c|c|c|c|c|c|c|c|c|c|c|c|c|c|}
\hline \multirow{2}{*}{ Parameter } & \multicolumn{2}{|c|}{ Pig 1} & \multicolumn{2}{|c|}{ Pig 2} & \multicolumn{2}{|c|}{ Pig 3} & \multicolumn{2}{|c|}{ Pig 4} & \multicolumn{2}{|c|}{ Pig 5} & \multicolumn{2}{|c|}{ Pig 6} & \multicolumn{2}{|c|}{ Mean value ( \pm SD) } \\
\hline & Before & After & Before & After & Before & After & Before & After & Before & After & Before & After & Before & After \\
\hline AH & 77 & 80 & 65 & 64 & 59 & 66 & 60 & 61 & 89 & 85 & 57 & 63 & $68 \pm 12.6$ & $70 \pm 10.1$ \\
\hline HV & 41 & 46 & 43 & 40 & 43 & 53 & 47 & 41 & 43 & 46 & 31 & 30 & $41 \pm 5.4$ & $43 \pm 7.7$ \\
\hline HRA-LA & 66 & 60 & 28 & 34 & 52 & 50 & 34 & 32 & 38 & 34 & 46 & 28 & $44 \pm 13.7$ & $40 \pm 12.5$ \\
\hline HRA-LA 150 & 82 & 92 & 84 & 60 & 110 & 118 & 54 & 64 & 68 & 64 & 76 & 98 & $79 \pm 18.7$ & $83 \pm 23.6$ \\
\hline LA-HRA 150 & 70 & 80 & 94 & 66 & 106 & 112 & 52 & 74 & 68 & 56 & 70 & 96 & $76 \pm 19.7$ & $81 \pm 20.4$ \\
\hline AV Wenckebach & 220 & 220 & 190 & 180 & 200 & 220 & 190 & 240 & 190 & 190 & 200 & 200 & $198 \pm 11.7$ & $208 \pm 22.3$ \\
\hline SNRT & 498 & 898 & 742 & 682 & 720 & 784 & 442 & 740 & 1030 & 814 & 672 & 792 & $684 \pm 208.6$ & $785 \pm 72.5$ \\
\hline CSNRT & 70 & 188 & 124 & 94 & 108 & 120 & 36 & 124 & 280 & 182 & 100 & 130 & $120 \pm 84.5$ & $140 \pm 37.2$ \\
\hline VERP 130 & 200 & 210 & 200 & 210 & 240 & 250 & 210 & 230 & 190 & 210 & 180 & 200 & $203 \pm 20.7$ & $218 \pm 18.3$ \\
\hline VERP 150 & 190 & 200 & 180 & 180 & 230 & 230 & 210 & 230 & 200 & 200 & 170 & 190 & $197 \pm 21.6$ & $205 \pm 20.7$ \\
\hline VERP 180 & 180 & 190 & 180 & 170 & 210 & 200 & 190 & 200 & 170 & 180 & 160 & 180 & $182 \pm 17.2$ & $187 \pm 12.1$ \\
\hline AERP 130 & 110 & 120 & 110 & 140 & 170 & 210 & 110 & 120 & 130 & 120 & 120 & 130 & $125 \pm 23.4$ & $140 \pm 35.2$ \\
\hline AERP 150 & 120 & 110 & 110 & 140 & 160 & 180 & 110 & 110 & 120 & 110 & 120 & 130 & $123 \pm 18.6$ & $130 \pm 27.6$ \\
\hline AVNERP 130 & 290 & 290 & 290 & 300 & 300 & 250 & 270 & 280 & 280 & 280 & 230 & 260 & $277 \pm 25.0$ & $277 \pm 18.6$ \\
\hline AVNERP 150 & 270 & 280 & 280 & 230 & 280 & 270 & 260 & 260 & 270 & 270 & 240 & 250 & $267 \pm 15.1$ & $260 \pm 17.9$ \\
\hline HR & 150 & 90 & 119 & 100 & 128 & 90 & 113 & 95 & 130 & 95 & 160 & 96 & $133 \pm 18.1$ & $94 \pm 3.8$ \\
\hline
\end{tabular}

Explanations: $\mathrm{AH}$ - the interval between the atrial stimulation and the bundle of His; HV - interval between the bundle of His and the ventricular stimulation; SNRT - sinus nodal reentrant tachycardia; CSNRT - corrected sinus node recovery time; HRA-LA - activation from the high right atrium to the left atrium; HRA-LA 150 - interventricular stimulation at 150/min; LA-HRA 150 - reverse interatrial conduction time at am induced heart rate of $150 / \mathrm{min}$, from the left atrium to the high right atrium; AV Wenckebach - the lowest atrial stimulation frequency at which there is an AV delay, in a 1:1 ratio; AERP 130, 150 - atrial effective refractory period during an externally induced heart rate of 130/min and 150/min; AVNERP 130, 150 - atrioventricular node effective refractory period externally induced heart rate of 130/min and 150/min; VERP 130/min, 150/min, 180/min - ventricular effective refractory period during an externally induced heart rate of 130/min, 150/min, 180/min; SD - standard deviation 


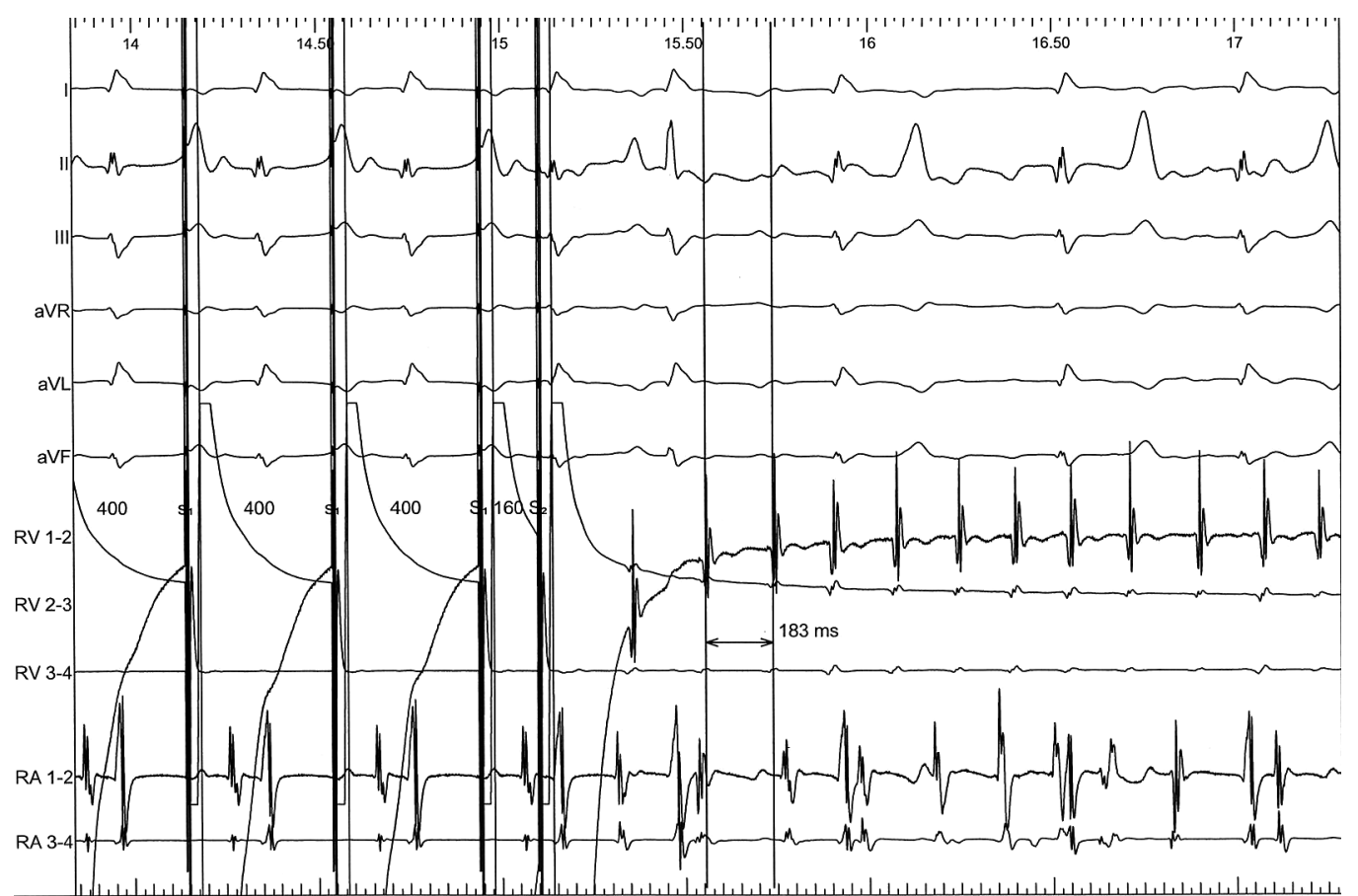

Fig. 1. Atrial flutter with an atrial cycle of $183 \mathrm{~ms}$ triggered during the gradual atrial pacing protocol with a shortened cycle in pig number 5 after the administration of xylazine (sweep speed $67 \mathrm{~mm} / \mathrm{s}$ )

anaesthetics, including isoflurane, protect the myocardium from ischemia. This mechanism of action is not fully understood, but it is believed that the relaxation of the coronary artery vascular smooth muscle and a decreased oxygen demand of the myocardium play an important role in the process $(12,30)$. No significant changes in cardiac conduction are likely to be caused by the cardioprotective effect of isoflurane. On the other hand, it has been shown that inhalational anaesthetics may sensitize the heart to catecholamines and thereby cause premature ventricular contraction (23). However, we did not observe ventricular arrhythmias. All the recorded arrhythmias were atrial, suggesting that they were caused by the alpha- 2 agonists. The hemodynamic and electrical effects of midazolam and propofol on the circulation are low (29).

A reduction in the heart rate was observed following the administration of the three substances, which is a known effect, already described in the literature. The main adverse effects of the alpha-2 adrenergic receptors on the cardiovascular system include a decrease in the cardiac output, an increase in systemic vascular resistance, bradycardia and bradyarrythmias, including first- and second-degree atrioventricular blocks $(10,14,24,33)$. The three drugs cause a reduction in the sympathetic tone and an increase in systemic vascular resistance, leading to bradycardia. Alpha-2 agonists reduce the release of noradrenaline in the OUN, inhibiting sympathetic activity. The desired effect of this mechanism is sedation, but it also reduces the heart rate. Alpha-2 agonists act on the peripheral receptors by significantly increasing systemic vascular resistance and causing an increase in blood pressure, which in turn triggers the baroreceptor reflex, leading to bradycardia. The lack of significant differences in the values of the electrophysiological parameters may be explained by the fact that, in general, pigs demonstrate a low response to alpha-2 adrenergic receptor agonists, particularly to xylazine $(8$, $31)$. The available literature suggests that, despite its weak anaesthetic effect, xylazine has the previously described cardiovascular effects (8). The intensity and duration of systemic vascular resistance is doseand route-dependent and is also affected by substance selectivity. At lower doses, the main effect is a block of the sympathetic autonomic nervous system via alpha-2 receptors, causing a decrease in blood pressure. At higher doses, there is an increase in arterial blood pressure and a decrease in the heart rate, caused by the stimulation of alpha-2B isoreceptors in the capillary smooth muscles (24). The initial increase in arterial blood pressure is greater following intravenous drug administration compared to intramuscular administration (34). Three different substances with varying alpha-2 selectivity compared to the alpha- 1 selectivity were analysed at a single dose. Dexmedetomidine was the most selective, although it caused the largest decreases in the heart rate. The initial heart rate was also the highest in that group, which may have affected the differences in the heart rate before and after drug administration. The only parameter that differed significantly among the groups was the change in the refractory period in the right ventricle at an induced heart rate of 130/min. These differences may have been caused by different electrode placements in the right ventricle during the first and second examinations. We did not find an explanation for the change in this single parameter in the available literature. The absence of changes in the remaining cardiac conduction parameters may be explained by the fact that the bradycardia we observed was caused by stimulation of the autonomic nervous system and systemic vascular resistance, not by changes in cardiac conduction. Despite the absence of statistically significant differences in the EPS parameters, we found a proarrhythmic activity of the drugs, particularly xylazine. The most common arrhythmias caused by alpha- 2 agonists described in veterinary literature include bradyarrhythmias, such as first- and second-degree atrioventricular blocks and sinus arrhythmias $(15,27)$. Third-degree atrioven- 
tricular block and cardiac arrest are rarely noted (17). We did not note such arrhythmias in our study. Those arrhythmias were triggered during the atrial stimulation protocol after administering the substances. The arrhythmias occurred most commonly in the pigs that received xylazine and were the least common in the group that received dexmedetomidine (one pig). Hence, xylazine seems to be the most arrhythmogenic of the three substances, which is in accordance with literature reports, stating that arrhythmogenicity decreases with an increased selectivity of alpha-2 agonists (16).

The results of this study indicate that medetomidine and dexmedetomidine may be added to the standard anaesthetic drugs used during electrophysiological studies in pigs. The use of these substances may facilitate animal preparation for electrophysiological procedures, while minimally affecting the results.

In order to draw clear conclusions, the arrhythmogenic potential of the three drugs needs to be studied on a larger group of animals. The study was carried out using only single-dose intravenous administration of the alpha-2 agonists. Hence, these factors should also be considered in future studies.

The study was conducted by financing by targeted subsidy and printed by financing from statute subsidy of the Department of Internal Diseases with the Clinic of Horses, Dogs and Cats, Wroclaw University of Environmental and Life Sciences.

\section{References}

1. Bedoya J., Meyer C., Timmins L., Moreno M., Moore J.: Effects of stent design parameters on normal artery wall mechanics. J. Biomech. Eng. 2006, 128, 757-765.

2. Bergen W. G., Mersmann H. J.: Comparative aspects of lipid metabolism: impact on contemporary research and use of animal models. J. Nutr. 2005, 135, 2499-2502.

3. Ching C. K., Burkhardt J. D., Dresing T., Natale A.: Venous and arterial access, EP catheters, positioning of catheters, [in:] Natale A., Wazini O.: Handbook of Cardiac Electrophysiology. Taylor\&Francis, London 2007, p. 222-228.

4. Cooper D., Gollackner B., Sachs D.: Will the pig solve the transplantation backlog? Ann. Rev. Med. 2002, 53, 133-147.

5. Coronel R., Francien J. G., Wilms-Schopman M. S., Joris R., de Groot M. D.: Origin of Ischemia-Induced Phase 1b Ventricular Arrhythmias in Pig Hearts. J. Am. College of Cardiol. 2002, 39, 166-176

6. Eubanks D., Cooper R., Boring J.: Surgical technique for long-term cecal cannulation in the Ucatan minipig (Sus scrofa domestica). J. Am. Ass. Lab. Anim. Sci. 2006, 45, 52-56.

7.Funke S., Markowitsch S., Schmelter C., Perumal N., Mwiiri F. K., GabelScheurich S., Pfeiffer N., Grus F. H.: In-Depth Proteomic Analysis of the Porcine Retina by Use of a four Step Differential Extraction Bottom up LC MS Platform. Mol. Neurobiol. 2016, DOI: 10.1007/s12035-016-0172-0

8. Gómez de Segura I. A., Tendillo F. J., Mascías A., Santos M., Castillo-Olivares J. L., Steffey E. P.: Actions of xylazine in young swine. Am. J. Vet. Res. 1997, 58, 99-102.

9. Green J., Kim J., Whitworth K., Agca C., Prather R.: The use of microarrays to define function ally-related genes that are differentially expressed in the cycling pig uterus. Soc. Reprod. Fertil. Suppl. 2006, 62, 163-176.

10. Haskins S. C., Patz J. D., Farver T. B.: Xylazine and xylazine ketamine in dogs. Am. J. Vet. Res. 1986, 47, 636-641.

11. Imai H., Konno K., Nakamura M., Shimizu T., Kubota C., Seki K., Honda F., Tomizawa S., Tanaka Y., Hata H., Saito N.: A new model of focal cerebral ischemia in the miniature pig. J. Neurosurg. 2006, 104, 123-132.

12. Kersten J. R., Schmelling T. J., Hettrick D. A., Pagel P. S., Gross D. J., Warltier $D$. $C$.: Mechanism of myocardial protection by isoflurane: role of adenosine tri-phosfate regulated potassium channels. Anesthesiology 1996, 85, 794-807.
13. Kouroupis D., Kyrkou A., Triantafyllidi E., Katsimpoulas M., Chalepakis G., Goussia A., Georgoulis A., Murphy C., Fotsis T.: Generation of stem cell-based bioartificial anterior cruciate ligament (ACL) grafts for effective ACL rupture repair. Stem Cell Res. 2016, 17, 448-457. doi: 10.1016/j.scr.2016.04.016

14. Lammintausta $R$. : The alpha-2 adrenergic drugs in veterinary anaesthesia. $4^{\text {th }}$ Proc. Int. Congr. Vet. Anaes. 1991, p. 3-8.

15. Lamont L. A., Bulmer B. J., Sisson D. D., Grimm K. A., Tranquilli W. J.: Doppler echocardiographic effects of medeomidine on dynamic left ventricular outflow tract obstruction in cats. J. Am. Vet. Med. Assoc. 2002, 221, 1276-1281.

16. Lemke K. A., Tranquilli W. J., Thurmon J. C., Benson G. J., Olson W. A.: Influence of cholinergic blockade on the development of epinephrine-induced ventricular arrhythmias in halothane- and isoflurane-anesthetized dogs. Vet. Surg. 1994, 23, 61-66.

17. Muir W. W., Mason D.: Cardiovascular System, [in:] Thurmon J. C., Tranquilli W. J., Benson G. J.: Veterinary Anesthesia. Philadelphia Williams and Wilkins, $3^{\text {rd }}$ ed. 1996 , p. 62-114.

18. Noszczyk-Nowak A., Cepiel A., Janiszewski A., Pasławski R., Gajek J., Pasławska U., Nicpoń J.: Normal Values for Heart Electrophysiology Parameters of Healthy Swine Determined on Electrophysiology Study. Adv. Clin. Exp. Med. 2016, 25, 1249-1254.

19. Noszczyk-Nowak A., Pasławska U., Gajek J., Janiszewski A., Pasławski R., Zyśko D., Nicpoń J.: Ventricular Effective Refraction Period and Ventricular Repolarization Analysis in Experimental Tachycardiomyopathy in Swine. Adv. Clin. Exp. Med. 2016, 25, 409-414

20. Pasławska U., GajekJ., KiczakL., Noszczyk-NowakA., SkrzypczakP., Bania J., Tomaszek A., Zacharski M., Sambor I., Dzięgiel P., Zyśko D., Banasiak W., Ponikowski P.: Development of a partial model of chronic tachycardia-induced cardiomyopathy. Int. J. Cardiol. 2011, 153, 36-41.

21. Penniston K. L., Patel S. R., Schwahn D. J., Nakada S. Y.: Studies using a porcine model: what insights into human calcium oxalate stone formation mechanisms has this model facilitated? Urolithiasis, 2016 Nov. 30. DOI: 10.1007/s00240-016-0947-9

22. Pires L. A., Stephen Huang S. K., Wagshal A. B., Kulkarni R. S.: Electrophysiological Effects of Propofol on the Normal Cardiac Conduction System. Cardiology 1996, 87, 319-324.

23. Prys-Roberts C., Meloche R.: Management of anesthesia in patients with hypertension and ischaemic heart disease. Int. Anesthesiol. Clin. 1980, 18, 181-217

24. Pypendop B., Verstegen J. P.: Hemodynamic effects of medetomidine in the dog: a dose titration study. Vet. Surg. 1998, 27, 612-622.

25. Sakaguchi M., Nishimura R., Sasaki N., Ishiguro T., Tamura H., Takeuchi A.: Sedative effects of medetomidine in pigs. J. Vet. Med. Sci. 1992, 54, 643-647.

26. Scheinin H., Virtanen R., MacDonald E., Lammintausta R., Scheinin M. Medetomidine - a novel alpha 2-adrenoceptor agonist: a review of its pharmacodynamic effects. Progr. Neuropsychopharmacol. Biol. Psychiatry 1989, $13,635-651$

27. Short C. E.: Effects of anticholinergic treatment on the cardiac and respiratory systems of dogs sedated with medetomidine. Vet. Rec. 1991, 129, 310-313.

28. Simon G. A., Maibach H. I.: The pig as an experimental animal model of percutaneous permeation in man: qualitative and quantitative observations - an overview. Skin Pharmacol. Appl. Skin Physiol. 2000, 13, 229-234.

29. Staikou C., Stamelos M., Stavroulakis E.: Impact of anaesthetic drugs and adjuvants on ECG markers of torsadogenicity. Br. J. Anaesth. 2013, published online doi: $10.1093 / \mathrm{bja} /$ aet412

30. Stoelting R. K., Miller J. D.: Effects of inhaled anesthetics on ventilation and circulation, [in:] Basics of Anaesthesia. Churchill Livingstone Inc., New York 1989, p. 43-56.

31. Straw B. E., Zimmerman J. J., D'Allaire S., Taylor D. J.: Diseases of Swine John Wiley\&Sons, West Sussex 2013, p. 1110.

32. Swindle M. M., Smith A. C.: Swine in the Laboratory: Surgery, Anesthesia, Imaging, and Experimental Techniques, CRC Press, Boca Raton 2015, p. 60.

33. Tan J. A., Ho K. M.: Use of dexmedetomidine as a sedative and analgesic agent in critically ill adult patients: a meta-analysis. Intensive Care Med. 2010,36, 926-939

34. Vainio O., Palmu L.: Cardiovascular and respiratory effects of medetomidine in dogs and influence of anticholinergics. Acta Vet. Scand. 1989, 30, 401-408.

35. Wang $X$., Mu G., Dang R., Yang Z.: Up-regulation of IL-10 upon PRRSV vaccination impacts on the immune response against CSFV. Vet. Microbiol. 2016, 197, 68-71. doi: 10.1016/j.vetmic.2016.11.007.

36. Zaballos M., Jimeno C., Almendral J., Atienza F., Patiño D., Valdes E., Navia J., Anadón M. J.: Cardiac electrophysiological effects of remifentanil: study in a closed-chest porcine model. Br. J. Anaesth. 2009, 103, 191-198.

Corresponding author: Alicja Cepiel DVM, PhD, PI. Grunwaldzki 47, 50-366 Wroclaw, Poland; e-mail: alicja.cepiel@up.wroc.pl 